\title{
Da formalidade da docência acadêmica à docência experienciada na escola
}

\section{Rosa Maria Maia Gouvêa Esteves}

Doutoranda em Tecnologias de Informação e Comunicação nos Processos

Educacionais pela Universidade Estácio de Sá (UNESA)

\section{Márcio Silveira Lemgruber}

Doutor em Educação pela Universidade Federal do Rio de Janeiro. Professor e Orientador do doutorado da Universidade Estácio de Sá (UNESA) 


\section{Resumo}

Este artigo objetiva, a partir das pesquisas desenvolvidas por Nóvoa (1992) e Tardiff (2012), e por outros pesquisadores que discutem a formação de professores, compreender que não é somente os saberes formais da academia que determinam o fazer do professor, mas que são essenciais outros saberes, como aqueles construídos ao longo de sua carreira, oriundos de suas práticas, à luz do que ocorre no cotidiano escolar, assim como aspectos de vida pessoal, que trarão novas discussões e avanços nos aspectos teóricos e práticos inerentes à carreira docente. Para tanto é importante que as pesquisas realizadas sobre o fazer dos professores considerem estes como sujeitos e não como meros objetos de investigação. Também propõe-se entender, por meio da metodologia desenvolvida por Nóvoa, por que alguns professores fazem uso da tecnologia da comunicação e da informação e outros não; o que se dá nesse processo que leva alguns professores a diferenciarem seus percursos pegagógicos de seus pares?

Palavras-chave: Formação Docente. Práticas Pedagógicas. Tecnologia

\section{Abstract}

This article aims, from the researches developed by Nóvoa (1992) and Tardiff (2012), and other researchers to discuss the training of teachers, understand that it is not only the formal knowledge of the Academy that determine the make of the professor, but which are essential others know, like those built over the course of your career, from their practices, in light of what occurs in school everyday as well as aspects of personal life, which will bring new discussions and advances in theoretical and practical aspects of teaching career. It is important that the research conducted on the making of teachers consider these as subjects and not as mere objects of research. Also proposes to understand, through the methodology developed by Nóvoa, why some teachers make use of communication and information technology and others do not; what goes around in this process that leads some teachers to differentiate their pegagógicos paths of their peers?

Keywords: Teacher Training. Pedagogical Practices. Technology 
Essa profissão precisa de se dizer e de se contar: é uma maneira de a compreender em toda sua complexidade humana. É que ser professor obriga a op̧ões constantes, que cruzam a nossa maneira de ser com nossa maneira de ensinar, e que desvendam na nossa maneira de ensinar a nossa maneira de ser (António Nóvoa).

\section{Introdução}

Pensar a carreira docente impõe reflexões e atitudes. Têm-se, por décadas, pesquisas dedicadas a entender as diferentes interfaces que cercam a carreira do professor. Uma dessas interfaces é sobre a formação de professores. As pesquisas desenvolvidas por Nóvoa (2013), há duas décadas, mostra a mudança do paradigma em termos da investigação da carreira docente, por meio de metodologias que permitem estudar a vida dos professores, de suas carreiras, dos seus percursos profissionais, de suas biografias ou autobiografias. O diferencial dessas pesquisas é que não visam somente a elucidar suas práticas pedagógicas, mas, principalmente, a buscar uma compreensão e lançar luzes sobre quem são essas pessoas e quem são esses profissionais que estão por trás dessa(s) prática(s)? Como esses Eus interagem para alavancar suas práticas docentes? Que interesses os movem? O que os motiva para tomada decisão? Nesse percurso, têmse autores como: Nóvoa (1992), Gomes (1996) Pretto (2009), Kenki (2009) Tardiff (2012), Pimenta (2012), Adorno (2012), Schaffel (2013),Goodson (2013) e outros que também discutem os saberes pedagógicos e formação continuada dos professores, em seu conteúdo e forma. 


\section{As pesquisas sobre formação de professores: novas propostas de imersão}

Mapeando esse novo caminho investigativo, Tardif (2012) realiza pesquisas no sentido de se conhecer quais saberes profissionais (formais) os professores utilizam efetivamente em seu cotidiano escolar, que relação existe entre os saberes profissionais e os conhecimentos acadêmicos; entre os professores da Educação Básica e os professores do Ensino Superior. Essas pesquisas apontam que os saberes dos professores provenientes de suas histórias da vida escolar e dos primeiros anos de prática profissional são decisivos para o estabelecimento de rotinas e construção de um sentimento de competência aprendido nas práticas da escola. Estas se solidificam, ao longo de suas carreiras, por meio de saberes heterogêneos provenientes de rigor formal (das disciplinas do curso da academia), pessoal (das histórias da vida) e experiencial (das práticas do cotidiano escolar) focados em suas ações, nas trocas com seus pares e em vivências ligadas às tradições do oficio da docência.

Assim, Nóvoa propõe (2013) que os professores sejam considerados nas dimensões pessoais e profissionais e aponta que o que sustenta o processo identitário dos professores são três instâncias: a adesão, a ação e a autoconsciência. Dentro dessa configuração proposta, ser professor implica em adesão a valores, projetos e crenças. Quando se fala em ação, esta está vinculada às escolhas pessoais e profissionais do professor, enquanto a autoconsciência foca o processo de reflexão sobre as questões da prática, no cotidiano escolar. O autor também fala em processo identitário, mas o que significa isto? Segundo Nóvoa, é como cada um se sente e se diz professor e que aponta para a capacidade de exercer com autonomia a atividade da docência, assim a maneira que cada um ensina depende de suas convicções pessoais. De acordo com o autor, é impossível separar o Eu profissional do Eu pessoal. 
Corroborando com as pesquisas de Nóvoa, os estudos de Goodson (2013) propõem que o ponto de partida para o entendimento das práticas docentes deve estar centrado na voz do professor e não somente no olhar sobre suas práticas, assim oferece um novo direcionamento para as pesquisas, em que a vida e trabalho do professor devem fazer parte da investigação para alargamento da visão do que consiste essa carreira profissional.

As pesquisas de Goodson (idem) ainda elucidam que a razão essencial para dar voz aos professores reside no fato de que temas pertencentes à escola como o desenvolvimento curricular, as matérias do ensino, o ensino eficaz, a organização geral da escola, a questão de inovações tecnológicas, o gerenciamento do espaço escolar e as novas iniciativas de gestão - estas colocações postas pelos professores - estão sempre sintonizadas com suas vivências e seus tempos na escola. As experiências e o estilo de vida, o ambiente pessoal e os estágios referentes à carreira são aspectos que vão impactar as práticas educacionais desses profissionais.

Aprofundando essas questões, Nóvoa (1992), em seu livro Formação de Professores e Profissão Docente, considera que o desenvolvimento pessoal produz a vida do professor, assim as escolhas realizadas enquanto pessoa, se refletem na produção da vida do docente, logo, não é o acúmulo de conhecimentos formalizados que faz esse profissional, mas as reflexões sobre suas práticas, que irão permanentemente reconstruir sua identidade. Por outro lado, tem-se que o desenvolvimento profissional, que é produzir a prática docente sintonizada com a valorização de paradigmas que formem professores reflexivos, responsáveis pelo seu próprio desenvolvimento; mas isso só terá concretude a partir de mudanças nos espaços de formação do professor, ao perceber que se tem uma sociedade globalizada, multimídia e em constante transformação em todas as áreas do conhecimento. E aí como essas questões que perpassam a sociedade hoje, influenciam mudanças que precisam ser realizadas na formação do professor e por consequência na escola? 
O pesquisador faz um alerta que é preciso investir nos saberes que o professor elabora durante sua trajetória, como dentre eles: os saberes da(s) prática (s), que não são possuidores de um caráter somente instrumental, mas carregam em sua essência uma série de circunstâncias, as quais o levam a determinar suas escolhas. Também aponta para a diversificação dos modelos e das práticas da formação, que devem proporcionar a experimentação, a inovação, os processos de investigação, articulados às práticas docentes e, finalmente, comenta sobre o desenvolvimento organizacional como caminho para mudar a escola.

As questões acima citadas estão interligadas e as mudanças na escola dependem da formação dos professores e das inovações nas práticas pedagógicas, mas também passam pela gestão administrativa e pedagógica, uma vez que essas mudanças precisam fazer parte do projeto político pedagógico das instituições de ensino, em consonância com a comunidade, levando-se em consideração o público alvo e suas peculiaridades como: pluralidade cultural, étnica, convicções religiosas, consumo e trabalho, e meio ambiente.

Pimenta (2012), em pesquisas sobre as práticas dos professores e sua identidade, com foco nos saberes que podem constituir a docência, ressalta que a construção da identidade do professor não é um dado imutável, pois ela se constitui em um determinado contexto histórico e nas práticas sociais, historicamente construídas; aponta para o caráter dinâmico da profissão docente, como ponto de partida na busca de referenciais para repensá-la. Mas, o que são práticas e teorias, quando uma começa e quando a outra finda? Será que existe a primazia de uma sobre a outra? Práticas podem ser consagradas sem que exista uma teoria que as sustente? As teorias podem se sustentar sem práticas? Caso se analise somente a prática pela prática, essa não terá nenhum sentido, esse sentido só virá a partir do momento, em que se pode ver quem pratica a ação. 
Assim, significados se constroem pela autoria de quem as pratica, isto é, revestido de suas histórias pessoais, de suas representações e de seus saberes advindos das experiências e dos momentos que foram construídas e para quem foram construídas, como um sinal de pertencimento. Nesse sentido, que saberes trazem os professores em suas diferentes fases profissionais de ser professor, que atingem e dão novos rumos a discussão da carreira docente?

Em primeiro lugar, os pretendentes às licenciaturas chegam aos cursos de formação inicial com as experiências e vivências que acumularam de seus professores durante suas trajetórias escolares, enquanto alunos; outra questão a ser comentada é pertinente ao conhecimento; professores sabem que lidarão com o conhecimento, e que precisam conhecer para ensinar, mas poucos se perguntam qual é a relação entre esse conhecimento que será ensinado, a sociedade contemporânea e o mundo do trabalho? Assim, qual é a finalidade da educação numa sociedade tecnológica, multimídia globalizada, e sua relação com a formação pessoal, as habilidades específicas e com o mundo do trabalho? Que competências os alunos precisam construir para estar neste mundo e serem sujeitos desse tempo histórico?

Por outro lado, Pimenta (2012, p.27) recomenda que "o retorno autêntico à pedagogia ocorrerá se as ciências da educação deixarem de partir de diferentes saberes constituídos e começarem a tomar a prática dos formados como ponto de partida e de chegada", portanto, é urgente que a didática contemporânea faça uma leitura crítica da prática social e do ensinar, ligado ao mundo real que se apresenta e aos atores envolvidos para que possa avançar e possibilitar outras leituras.

Assim, a autora ressalta a busca das novas contribuições da psicologia e da sociologia, assim como das iniciativas de mudanças de métodos, de currículos e da própria mudança na formação inicial do professor. Ainda coloca que o futuro professor não pode constituir seu saber-fazer senão a partir de seu próprio fazer, também aponta o 
registro da prática para a constituição de teorias. Saber-fazer parte do fazer, é algo para se debruçar, porque essa habilidade só se adquire à luz da experiência.

Pimenta (idem) contribui clarificando que nas práticas dos professores existem elementos importantes como: (a) o enfretamento das situações-problema, (b) a problematização, (c) a intencionalidade; (d) a experimentação metodológica; (e) a didática inovadora (ainda não escrita), e a existência de passos a serem registrados.

É o estudo da experiência para modificar a teoria. Isso requer uma atitude de investigação da realidade escolar, quando se pratica uma reflexão sobre a ação para avançar na experimentação metodológica e escrever uma outra teoria, fundada no percurso biográfico e experiencial do professor.

Qual é a importância dessas questões acima elencadas? Será que os professores percebem que essas situações provocam e remetem a caminhos desconhecidos, como num labirinto, em que se procura a saída? O professor terá que possuir uma percepção afinada para lidar com questões investigativas e na busca de estratégias para encontrar soluções, que não são explicitadas, em relatados escritos. Então, que saberes (os conhecimentos, o saber-fazer, as competências e as habilidades) os professores mobilizam, diariamente, em suas salas de aulas, a fim de realizar concretamente as suas diversas tarefas, nem sempre ou quase nem sempre escritas, pois fazem parte do saberfazer e que modificam o saber?

O saber é sempre o de alguém que trabalha algo no intuito de alcançar um objetivo qualquer. Além disso, o saber não é uma coisa que flutua no espaço: o saber dos professores é deles e está relacionado com a pessoa e suas identidades, com suas experiências de vida e suas histórias profissionais, com suas relações com os alunos em sala de aula, com seus pares e outros atores participantes da escola. 
A abordagem de Tardif (2012) em relação a como se constitui o saber dos professores foge de dois princípios: (a) do mentalismo - campo das Ciências Cognitivas $^{1}$ : construtivismo ${ }^{2}$ e o socioconstrutivismo ${ }^{3}$ radical que reduz o saber em um processo mental e (b) do sociologismo - um saber social, que elimina a contribuição dos autores e o subordinada às forças sociais.

Em relação ao mentalismo, o autor defende que um saber social é compartilhado por um grupo de professores, está repousado em um sistema para garantir sua legitimidade. O saber profissional do docente é o resultado de negociação entre diversos grupos; o objeto de estudo é próprio objeto social (os alunos); assim, o saber não é um produto, um objeto ou um conteúdo fechado em si mesmo, ele se manifesta por meio das relações entre professor e aluno; o saber advindo da história das disciplinas escolares, da história dos programas escolares, das ideias e das práticas dos professores são construções sociais, cujos conteúdos, formas e modalidades dependem da história de sociedade, dos programas das disciplinas e das práticas inseridas. Esse saber social pode ser adquirido no contexto de uma socialização profissional, quando é incorporado, modificado, adaptado em função dos momentos e das fases da carreira docente e das demandas.

${ }^{1}$ Cièncias Cognitivas surgem no final da década de 1950, como um movimento interdisciplinar interessado pelo estudo da cognição humana com pesquisas que elucidem os estudos sobre a relação entre o cérebro e a mente. Cientistas criaram um Programa Especial Sloan em Ciência Cognitiva composta por seis disciplinas: a psicologia, a lingüística, a neurociência, a ciência da computação, a antropologia e a filosofia. (NEUFEL, C.B.; BRUST, G.P.; M. STEIN, L. Psicologia: Teoria e Pesquisa, Brasília, Jan-Mar, Vol. 27 n. 1, pp. 103-112)

${ }^{2}$ Construtivismo é uma teoria criada por Piaget, segundo a qual as estruturas da inteligência, são produto de uma construção do indivíduo, decorrente da sua ação sobre o meio. A percepção é construída a partir de informação sensorial, mais do que uma resposta direta a estímulos, é uma construção com base em operações cognitivas e afetivas. MESQUITA.R. \& DUARTE F.Dicionário de Psicologia. Portugal: Plátano S.A, 1996.

${ }^{3}$ Sociocontrutivismo radical [...] Podemos defini-lo como uma tese filosófica sobre o conhecimento que pretende romper com as posições-padrão da epistemologia ao defender novos significados para conceitos como verdade, realidade e conhecimento. Glasersfeld (1989b; 1996) resume [ em ] duas proposições básicas: (1) o conhecimento não é passivamente recebido através dos sentidos ou por meio de comunicação, mas é ativamente construído pelo sujeito cognoscente; (2) a função da cognição é adaptativa e serve para a organização do sujeito de seu mundo experiencial, e não para a descoberta de uma realidade objetiva. MAZZONII \& CASTAÑON. Psicologia em Pesquisa - UFJF 8(2)|230-240, Julho-Dezembro de 2014. Disponível em:<http://pepsic.bvsalud.org/pdf/psipesq/v8n2/12.pdf〉. Acesso em: 09.08.2015. 
No tocante ao sociologismo, é impossível entender o saber dos professores sem que este saber esteja relacionado aos seus pares, em seus espaços profissionais; lembrando que o saber dos professores está sempre relacionado a uma situação de trabalho com os outros, isto é, um saber ancorado no ensino, num determinado espaço (sala de aula), pertencente a uma instituição.

\footnotetext{
A minha perspectiva procura, portanto, [situar] o saber do professor na interface entre o individual e o social, entre o ato e o sistema, a fim de captar a sua natureza social e individual como um todo. (TARDIF, 2012, p.16).
}

Tardif dedicou-se ao entendimento desse saber que é fundamental para a história da humanidade, afinal os professores constroem suas histórias, as dos outros e as de todos, pois, grande parte da vida dos indivíduos é passada nas escolas.

Tardif (2012, p. 228) coloca como ponto central para discussão nas pesquisas educacionais que "os professores de profissão possuem saberes específicos que são mobilizados, utilizados e produzidos por eles no âmbito de suas tarefas cotidianas" e deve-se considerá-los como autores ou até coautores participantes das pesquisas e não como objeto das pesquisas, uma vez que mediam a cultura, estão em relação direta com os alunos, com seus pares e demais agentes escolares. Suas falas e suas percepções devem ser levadas em conta, dentro dessa nova perspectiva investigativa.

Assim, Tardif abandona o viés da pesquisa que parte da visão tecnicista e sociologista, por despojar os participantes de seus saberes, e traz para o centro da discussão os professores como sujeitos do conhecimento e discute a subjetividade dos professores, nunca levada em consideração, pois as pesquisas sempre foram concebidas dentro de uma visão cartesiana e por isso essas questões sempre foram banalizadas e descartadas. Assim, o pesquisador vê o professor como aquele que assume sua prática a partir de suas escolhas, produz um saber-fazer a partir da sua ação, e aponta que as pesquisas precisam levar em conta o ponto de vista dos professores, seu saber-fazer, seus 
conhecimentos academicamente adquiridos, suas falas sobre seu oficio, não só para inovar os caminhos metodológicos da pesquisa, como para sinalizar novos achados.

O autor ainda discute o fato de como teoricamente tem sido abordada a questão da subjetividade dos professores nas investigações sobre ensino e prática docente, pautando seus estudos em três diferentes correntes do pensamento, que tratam a subjetividade: cognitiva, existencial e social, as quais oferecem percepções diferenciadas do professor (pessoa) e do seu trabalho. $\mathrm{Na}$ América do Norte, dentro da visão das ciências cognitivistas, a ação do professor é vista como um processo mental que conduz sua ação, seja na gestão da sala, ou na aplicação da sua aula aos alunos. Entretanto, na Europa, as pesquisas seguem a linha construtivista e/ou socioconstrutivista, em que as representações mentais do professor estarão relacionadas com os alunos, com seus pares, com ensino, com os programas, que conduzem a uma visão instrumental do professor, resultando em um quadro teórico traçado de seu perfil, que apontam características a serem preenchidas.

Já a visão existencial não se limita às representações mentais, o professor é visto de forma integral, com suas emoções, afetos, experiências e história de vida, tudo será primordial na tomada de decisão dos diferentes conflitos em sala de aula, contraponto com uma visão burocratizada e normativa da escola. E, para finalizar a visão sociológica, as pesquisas focam que a prática do professor está vinculada às regras sociais e ao que é comunicado por estes autores, isto é, "as competências e saberes dos professores são vistos como estritamente subjetivos, pois são socialmente construídos e partilhados” (TARDIF, 2012, p. 233).

A compreensão de cada corrente remete a diferentes conclusões, ora o professor está engessado em padrões pré-definidos do esperado de suas práticas, ora encontra-se livre das amaras, uma vez que os saberes sociais construídos envolvem uma série de atitudes na tomada da decisão, quando o docente mobiliza conhecimentos, habilidades e diferentes recursos pessoais para resolver os conflitos, seja na gestão da aprendizagem de seus alunos ou nas relações interpessoais da sala de aula, e até na discussão com seus 
pares para resgatar situações ainda não equacionadas, sendo essas atitudes pautadas em objetivos e metas que tenham sido traçados pelo grupo, num determinado planejamento.

Essas diferentes visões da subjetividade levam a diferentes tendências que vão configurar modos operantes do professor, porque conforme a concepção que assume, o resultado virá em atitudes que irão influenciar o ensino-aprendizagem, apostando-se , portanto, que o professor constrói seus conhecimentos também socialmente, no convívio com seus pares, pais e alunos e que as normas não estão pré-determinadas para todas as situações e serão construídas no cotidiano escolar de forma interativa, é uma mudança no polo das pesquisas até aqui realizadas.

Nesse ponto, outras questões são suscitadas como a relação entre teoria e prática e o ensino e a pesquisa, pois, ao considerar o professor como produtor de conhecimento, sujeito ativo e autor, não se pode dizer que os professores são meros aplicadores de teorias, produzidas nas universidades, muitas vezes desprovidas do cotidiano das escolas. No tocante à pesquisa universitária, alguns parâmetros precisam ser considerados: os professores devem ser vistos como sujeitos do conhecimento e colaboradores na investigação; o desenvolvimento de pesquisa para o ensino com a participação efetiva dos professores; e que os professores sejam capazes de se tornarem atores e produtores e que compartilhem suas práticas.

O trabalho - como toda práxis - exige, por conseguinte, um sujeito do trabalho, isto é, um ator que utiliza, mobiliza e produz os saberes de seu trabalho. Não poderia ser diferente com os professores, os quais realizam um trabalho que não é simples nem previsível, mas complexo e enormemente influenciado pelas próprias decisões e ações desses atores (TARDIF, 2012, p.236 e 237).

Em relação ao enfrentamento da formação dos professores, ainda muito dominada pelos conteúdos formais e não profissionais, que se abra um espaço para o conhecimento prático no currículo formal e que as disciplinas aprendidas de forma estanque, dentro da lógica disciplinar, que não cria possibilidade para a 
interdisciplinaridade, consecutivamente, observa-se um currículo em que o aluno tem uma atitude passiva, ouve muito e depois, em seus estágios, recorre à aplicação dos conceitos postos nas diferentes disciplinas. Perpassando essa discussão, o autor coloca que existe a desvalorização que os professores sofrem de seus pares, pois acreditam que dependendo do nível em que atuam, podem ser superiores aos seus colegas de profissão por seus conhecimentos teóricos e práticos.

Assim, chega-se a uma epistemologia da prática. Mas, o que é epistemologia da prática? Segundo Tardif (2013, p.255), "é o estudo do conjunto dos saberes utilizados realmente pelos profissionais em seu espaço de trabalho cotidiano para desempenhar todas as tarefas". De que saberes fala o autor? Num sentido amplo, são os conhecimentos, as competências e as habilidades (ou aptidões), traduzidos em saber, saber-fazer e saber-ser. E o que busca uma epistemologia da prática? Como os saberes estão integrados às práticas? Qual é a natureza desses saberes e que papel desempenham em relação ao trabalho e à identidade profissional do docente?

Tomando por base tais considerações, enumeram-se algumas consequências de tal definição: (a) foco na realidade; (b) a prática profissional não é aplicação dos conhecimentos universitários, isto é, não há uma relação direta entre o conhecimento formal da academia e a prática; (c) os pesquisadores devem ir aos locais de trabalho para verificarem in loco, como os professores interagem em diferentes situações do cotidiano escolar; (d) considerar os saberes dos professores como um conjunto de conhecimentos para a formação docente; (e) elaboração de pesquisas que levem em consideração os acontecimentos do cotidiano escolar e dos professores e (f) conceitos e práticas, em oposição à didática e à pedagogia.

E, segundo esta definição, algumas características dos saberes profissionais precisam ser levados em conta numa investigação neste paradigma: (a) saberes temporais - construídos ao longo da carreira docente; (b) saberes plurais e heterogêneos - que passam a ser mobilizados de acordo com situação ensino-aprendizagem e objetivos a serem atingidos (c) saberes personalizados e situados - como a docência é uma profissão 
de interação humana, suas ações passam a ser mediadas por suas características pessoais e sintonizados com aquele momento.

Guardadas as devidas proporções, Adorno (1995) quando entrevistava os futuros professores em Filosofia, que concorriam para preenchimento de vagas na Universidade, o que prendia sua atenção nestas entrevistas era a forma como os candidatos se posicionavam diante das questões propostas nas entrevistas, e suas respostas eram norteadas pelas disciplinas profissionais estudadas em sua formação, contudo o que mais interessava a Adorno era perceber como os futuros professores lincavam as discussões da atualidade com os conhecimentos acadêmicos e perceber como a Filosofia se entrelaçava com a vida. Preocupava-se que não fossem meros reprodutores de teorias, mas que estas teorias servissem para a reflexão da vida, uma vez que formavam os intelectuais de um país. Esse pensamento de Adorno reforça a ideia de que os saberes (conhecimentos) não são suficientes para formar um professor.

Schaffel (2013) contribui com outras questões quando discute a identidade profissional do professor que se "centra nos processos de adaptação do professor ao seu meio" e ainda traz ideias de outros autores, dentre eles Foucault (2012), sobre a relação entre poder e discurso e que os docentes se fortalecem à medida que possuem um discurso que lhes confere autoridade e que esse processo de construção de identidade está em aberto, pois é permeado por mudanças em diferentes espaços, que impactam tanto a profissão como a pessoa do professor.

Caso se analisem as pesquisas a partir do discurso e que se dê voz ao professor, pois é autor, essas questões precisam ser consideradas, uma vez que influenciarão a esfera acadêmica e as políticas públicas, tanto na formação dos docentes, como na organização dos espaços escolares e gestão pedagógica das escolas. Apropriar-se do que Foucault (2012) diz em A Ordem do Discurso remete para muito além das pesquisas.

A educação, embora seja, de direito, o instrumento graças ao qual todo indivíduo, em uma sociedade como a nossa, pode ter acesso a qualquer tipo de discurso, é bem sabido que segue, em sua distribuição, no que permite e no que impede, as linhas que estão marcadas pela distância, 
pelas oposições e lutas sociais. Todo sistema de educação é uma maneira política de manter ou de modificar a apropriação dos discursos, com os saberes e os poderes que eles trazem consigo (FOUCAULT, p.41,2012).

Deve-se estar atento se o discurso é distribuído para o controle. Então, questões que revestem as pesquisas as quais focam a carreira docente, soam como um alerta, ao inverterem a ordem do discurso e colocar os professores no centro, como autores e não como objeto das pesquisas. Tomar o que Foucault elucida é um ponta pé significativo no direcionamento de pesquisas que apresentam outras faces da questão investigada.

Pretto (2013), em sua obra Uma escola sem/com futuro alerta para a passagem da velha escola para a escola com futuro, ao falar da revisão da formação do professor e do papel das universidades frente aos desafios da tecnologia e ainda levanta outros quesitos importantes, como a questão salarial, a valorização do professor, seu nível de autonomia na sua profissão, a má formação e o professor visto ainda como um cumpridor de tarefas.

\footnotetext{
Iniciar, hoje, a formação do novo educador é premente. Um significativo passo nessa direção é considerar, no cotidiano da sua formação, as questões da comunicação, da informação e das imagens, com o objetivo de tornar os novos profissionais preparados para vivenciar os desafios do mundo que se está construindo (PRETTO, 2013, p.141).
}

Veem-se outros elementos incorporados ao debate, como acessar e lidar com os conteúdos das tecnologias da informação e da comunicação em sala de aula; sobre a condução do processo ensino-aprendizagem, usufruindo do uso do meio digital para o desenvolvimento de outras linguagens que possam sensibilizar o aluno para o aprendizado de conhecimentos de diferentes áreas, e não como um recurso colocado do lado de fora do muro da escola, pois os professores não se sentem parte dessa discussão. Falar sobre essas questões - educação e comunicação - ainda suscita dúvidas de como um campo pode conversar com o outro e, principalmente, como a educação pode apropriarse dos saberes da comunicação, constituindo uma nova área do saber. Como tirar partido para avançar e construir uma nova escola? 
Kenski (2009) faz vários questionamentos a respeito do que seria válido pensar sobre a formação de professores, se não deveríamos formar professores flexíveis e adaptáveis, voltados para a adequação aos desafios postos por uma sociedade em constante evolução? Como deveriam compor os conhecimentos de sua formação geral e específica e sua autonomia para a escolha da metodologia mais apropriada para o desenvolvimento de conteúdos com seus alunos? Pensar numa formação que lide diretamente com as mídias para possibilitar uso desses recursos (uso do computador, das redes e dos suportes midiáticos) em sala de aula, criando possibilidades de estratégias de aprendizagem.

Kenski (idem) propõe uma escola que vá além do ensino, que requer pensar os tempos de estudo, rigidamente definidos e que precisam ser redimensionados: como os períodos letivos, os tempos da hora/aula, os tempos do ensinar e do avaliar, os tempos de aplicação dos currículos, os tempos do planejar, todos devem ser pensados à luz de processos flexíveis, e que tome como bússola, o que aponta o Relatório da UNESCO para a escola do século XXI, coordenado por Jacques Delors (1998), tendo com aliadas as tecnologias da informação e da comunicação neste novos tempos, de urgência do novo e do inesperado frente ao desenvolvimento tecnológico.

A autora ainda elucida:

\footnotetext{
A formação do professor para atender às novas exigências originárias da "cultura informática" na educação precisa refletir esses mesmos aspectos. O mais importante deles é, sem dúvida, a percepção de que a atualização permanente é a condição fundamental para o bom exercício da profissão docente (KENSKI, p.88, 2009).
}

É preciso que o professor possa trocar e dialogar com sua realidade, alunos, pares, com as mais diferentes instituições nacionais e internacionais, crie possibilidade de intercâmbios, perpassando pela educação formal e informal. Construa projetos, desenvolva a criatividade dos alunos, o espírito de equipe, de solidariedade, de respeito, valores necessários para estar num mundo conectado em rede. 
Em contrapartida, se faz necessária uma série de providências como o investimento em políticas públicas em que, além do investimento na formação inicial, também haja um projeto de investimento na carreira do professor e na melhoria de suas condições de trabalho. Assim, pensar a escola e a carreira docente são questões inseparáveis na discussão para atender as novas demandas da sociedade da comunicação mediada pela linguagem digital.

Gomes (1996) faz uma reflexão, neste novo contexto informatizado, sobre o papel dos professores como gestores da sala de aulas, um designer de currículos, que não é protagonista sozinho, mas com seus alunos que se tornam gestores dos espaços da aprendizagem, que urge uma nova proposta, em outros ambientes, de forma colaborativa, que possa contemplar os diferentes estilos dos alunos, e com metodologias que levem o aluno a pensar em possíveis soluções, frente às questões dadas. Surgem novas competências a serem adquiridas para enfrentamento das mudanças em todas as áreas do conhecimento, potencializadas pela Internet.

\section{Considerações finais}

A escola, que tem como função social preparar as futuras gerações, se vê deslocada em como lidar com tantas questões, entre elas: como formar professores que possam estar inseridos nessa nova realidade de um mundo conectado e de alunos conectados; como lidar com uma educação informal, cada vez mais disponibilizada na Web? O que caberá à escola e aos professores, nessa nova lógica, com tantos conteúdos abertos por muitas instituições governamentais e não-governamentais, uma vez que o professor não é mais o único que detém o conhecimento? O grande desafio que se apresenta é: o que ensinar e como ensinar para uma sociedade que sempre construiu o futuro, mas .... qual é o futuro? Aí, começa a ser redesenhado um outro papel para a escola: como ensinar aos alunos a pesquisarem e selecionarem tudo que encontram na 
Internet, de que forma otimizar suas pesquisas, que fontes são confiáveis para a navegação? Como discutir os aspectos autorais dos conteúdos disponibilizados na Internet?

Aos professores cabem reflexões: como conviver e utilizar as linguagens híbridas? Será que qualquer material didático se presta e essa finalidade? Qual deve ser a linguagem argumentativa dos textos escritos e orais (bipertextos, biperlinks, podcasting)? Que tipo de informação deve conter? Comportam fotos e filmes, simultaneamente? Como construir textos que se complementam? Que estratégias motivacionais devem ser utilizadas para as aulas disponibilizadas num ambiente virtual de aprendizagem? Haverá videoaulas, que os alunos poderão acessar por meio de plataformas de suas casas?

Jogos interativos para desenvolvimento dos conteúdos disciplinares, interdisciplinares e/ou transdisciplinares? Até que ponto os professores são autores nesse processo, num desenvolvimento em espiral, ao perceberem que podem elaborar seus próprios conteúdos e colocá-los em plataformas, portais, blogs e serem protagonistas de suas histórias e de outras histórias? Carece de saber lidar com o que já está pronto e reinventar práticas que possam sensibilizar os alunos, tornando-os curiosos, investigativos que se sintam mobilizados para o aprendizado.

Segundo Zuffo (2009, p. 333), “a nova escola deve formar indivíduos criativos, flexíveis com espírito crítico, cidadãos que saibam viver e conviver em sociedade, capazes de reconhecer problemas, buscar e criar soluções”, uma vez que com o avanço da tecnologia, fica evidente que os indivíduos precisam ter ferramentas para saberem buscar seus conhecimentos com autonomia, a escola deve proporcionar oportunidades de aprendizagem para que os alunos busquem a solução dos problemas e com isso possam desenvolver habilidades para a vida e que possam continuar buscando sempre novas aprendizagens. Esses são alguns desafios colocados para os professores do século XXI, rever sua formação inicial e continuada, mas pautada em outros processos investigativos, como é proposto pelos autores, aqui, referendados. 


\section{Referências}

ADORNO, T. W. Educação e emancipação. Trad. Wolfgang Leo Maar. 7.ed. Rio de Janeiro: Paz e Terra, 1995.

DELORS, Jacques. Educação: um tesouro a descobrir. Relatório para a UNESCO da Comissão Internacional sobre Educação para o século XXI. São Paulo: Cortez, 1998.

FREIRE, P. Pedagogia da autonomia: saberes necessários à prática educativa. 29.ed. São Paulo: Paz e Terra, 2004.

FOUCAULT. M. A ordem do discurso: aula inaugural no Collège de France, pronunuciada em 2 de dezembro de 1970. Tradução Laura Fraga de Almeida Sampaio. 22ed. SãoPaulo: Loyola, 2011.

GOMES, M.J. Algumas Reflexões em torno da fundamentação da utilização educativa de sistemas hipermedia. Um problema sem solução ou uma solução à procura de fundamentação?.Revista Portuguesa De Educação, 1996, 9 (2), 43-59. 1996, I.E.P. Universidade do Minho. Disponível em <https://repositorium.sdum.uminho.pt/bitstream/1822/495/1/MARIAJOAOGOMES \%2520(43-59).pdf.> Acesso em 09.08.2015.

GOODSON, I.F. Dar voz ao professor: as historias de vida dos professores e o se desenvolvimento profissional. In: Nóvoa. A. (org.). Vidas de Professores. Portugal: Porto, 2013.

KENSKI, V. M. Educação e Tecnologia. 5. ed. Campinas, SP: Papirus, 2009. Tecnologias e ensino presencial e a distância. 7.ed. Campinas, SP: Papirus,

MAZZONII e CASTAÑON. Psicologia em Pesquisa - UFJF 8(2)|230-240, JulhoDezembro de 2014. Disponivel em:

<http://pepsic.bvsalud.org/pdf/psipesq/v8n2/12.pdf>. Acesso em: 09.08.20152009.

MESQUITA,R.\& DUARTE F.Dicionário de Psicologia. Portugal: Plátano S.A, 1996.

NEUFEL, C.B.; BRUST, G.P.; M. STEIN, L. Psicologia: Teoria e Pesquisa, Brasília, Jan-Mar, Vol. 27 n. 1, 2010, pp. 103-112 
ESTEVES, R. M. M. G.; LEMGRUBER, M. S. Da formalidade da docência acadêmica à docência experienciada na escola. R. Cientifica UBM - Barra Mansa (RJ), ano XXII, v. 19, n. 36, 1. Sem. 2017. p. 126-145.

NÓVOA, A. (org.). Vidas de Professores. Portugal: Porto, 2013.

Os professores e a sua formação. Lisboa: Dom Quixote, 1992. ISBN 972-20-

1008-5. pp. 13-33 http://repositorio.ul.pt/handle/10451/4758. Acesso em 05.06.2015.

PRETTO, N. DE L. Uma escola sem/com futuro: educação e multimídia. 7.ed. CampinasSP, Papirus, 2009.

TARDIF, M. Saberes docentes e formação profissional. 14.ed. Petrópolis, RJ: Vozes, 2013.

SCHALFFEL, L.S. A identidade profissional em questão. In: CANDAU, Vera Maria (org.). Reinventar a escola. 9. Ed. Petrópolis, RJ: Vozes, 2013.

SCHELL, J. Sete mitos sobre sala de aula invertida. Disponível em:

http://blog.peerinstruction.net/7-mitos-sobre-a-sala-de-aula-invertida-desmitificados/ consulta realizada em 30/10/2015.

ZUIN at al. Adorno: o poder educativo do pensamento crítico. 4.ed. Petrópolis, RJ:

Vozes, 2013.

ZUFFO, M. Aprendizagem por meio de ambientes de realidade virtual. In: LITTO,

Fredric Michael; FORMIGA, Marcos (org.) Educação a distância: o estado da arte. São Paulo: Pearson Education do Brasil, 2009. 